\title{
Original Article \\ Preliminary Investigation of Microplastics in Sediments from Industrial Manufacturing Waste Sources
}

\author{
Doan Thi Oanh ${ }^{1}$, Duong Thi Thuy ${ }^{2, *}$, Nguyen Thi Nhu Huong ${ }^{2}$, \\ Hoang Thi Quynh ${ }^{2}$, Phung Duc Hieu ${ }^{2}$, Dang Minh Vu ${ }^{3}$, Vu Thi Nguyet ${ }^{2}$, \\ Le Thi Phuong Quynh ${ }^{2}$, Bui Van Cuong ${ }^{2}$, Bui Huyen Thuong ${ }^{4}$ \\ ${ }^{1}$ Hanoi University of Natural Resources and Environment, 41A Phu Dien, Bac Tu Liem, Hanoi, Vietnam \\ ${ }^{2}$ Vietnam Academy of Science and Technology, 18 Hoang Quoc Viet, Cau Giay, Hanoi, Vietnam \\ ${ }^{3}$ VNU University of Science, 334 Nguyen Trai, Thanh Xuan, Hanoi, Vietnam \\ ${ }^{4}$ University of Science and Technology Hanoi, 18 Hoang Quoc Viet, Cau Giay, Hanoi, Vietnam
}

Received 21 September 2021

Revised 25 October 2021; Accepted 27 October 2021

\begin{abstract}
Microplastics (particles with a size of less than $5 \mathrm{~mm}$ ) are a rising environmental problem. Microplastics can disseminate in the air and accumulate in sediments as well as in microorganisms and humans, due to their small size. Sediment is considered to be the major repository of microplastics, particularly those of the PE type. Microplastics in massive amounts accumulated in sediments, perhaps as a result of point sources or diffuse contamination. Microplastic contamination can spread from industrial production facilities, urban areas, agricultural areas, or the air. The current study was carried out to explore the occurrence of MPs in sediments at discharge sources by evaluating 27 sediment samples taken from 9 distinct waste sources at industrial activity locations to determine the amount of microplastic contamination in sediments at discharge sources. Microplastics with a relatively high density were found in all sediment samples in this research, ranging from 2,900 to 238,200 particles $/ \mathrm{kg} \mathrm{dw}$. The most prevalent microplastics detected in sediment samples at these sites were fibers and fragments, accounting for $59-94 \%$ and $6-41 \%$, respectively. Fiber microplastics ranged in size from 1000 to $9,000 \mu \mathrm{m}$, whereas fragment microplastics ranged from 200,000 to 2,100,000 $\mu \mathrm{m}^{2}$. Microplastics with $<1000 \mu \mathrm{m}$ and 1000-2000 $\mu \mathrm{m}$ sizes accounted for a significant portion of the total, reaching $21.05-37.84 \%$ and $39.74-61.17 \%$, respectively. The hue of microplastic particles in sediment samples obtained was highly varied.
\end{abstract}

Keywords: Fragment, fiber, microplastics, sediment, waste source.

\section{Introduction}

Plastics are synthetic and semi-synthetic organic polymers derived from fossil fuels

\footnotetext{
* Corresponding author.

E-mail address: duongthuy0712@gmail.com

https://doi.org/10.25073/2588-1140/vnunst.5336
}

(coal, natural gas, or crude oil) and natural organic products including cellulose and regenerative compounds (grain, corn, etc.), which can be formed into different desired shapes [18]. Plastics have many superior characteristics, such as corrosion resistance, low weight, high durability, and low cost. Therefore, compared to other materials, plastics 
have been widely used in a variety of fields such as packaging, construction, transportation, healthcare, household appliances, electricity, electronic equipment, etc.

Microplastics are plastics that are less than $5 \mathrm{~mm}$ in size. With their small and very small sizes, microplastics are capable of spreading widely in the air, accumulating in sediments as well as in the bodies of microorganisms and humans. Currently, microplastics have been observed in almost all terrestrial ecosystems, freshwater, marine, and air, from agriculture to industrial zones, urban areas, or even remote areas.

Sediment is considered a large reservoir of microplastics. Large amounts of microplastics are accumulated in sediments, possibly through point sources or diffuse pollution. The origin of diffuse microplastic pollution could be from industrial plastic manufacturing facilities, runoff from urban, agricultural, industrial areas and the ambient air [17]. Wastewater treatment plants are believed to be an important point source of microplastic emissions, especially fiber microplastics. Murphy et al., (2016) estimated that a wastewater treatment plant could release 65 million microplastic particles into the receiving water source every day [11]. The production of cosmetics, personal care products, textiles, paints, and car tires are also considered sources of microplastics. Through domestic or industrial drainage systems, microplastics follow the water stream to the wastewater treatment plant, and can eventually be discharged into water bodies and/or dispersed in the sludge [12]. Sun et al., (2019) declared that the microplastic removal efficiency after going through the wastewater treatment systems could reach 95\% [15]. But with $5 \%$ of the remaining microplastics in the output wastewater or the sludge, it is still a relatively large number. The sludge from wastewater treatment is often reused in agriculture, landfilling, or incineration, but these methods all provide opportunities for microplastics to enter the environment and constitute serious environmental threats [13].

In general, there is still a significant knowledge gap about the role of waste sources in the microplastic occurrence in the soil, water, and air environment, especially in the sediments. In Vietnam, researchers are still trying to elucidate the level of microplastic pollutionin the soil, water, air, etc., in order to come up with management measures to prevent microplastic accumulation in the environment. Therefore, this study was carried out with the goal of determining the current status of microplastic pollution at some waste sources in order to assess the influence of these waste sources on the microplastic accumulation at the studied sites.

\section{Methodology}

\subsection{Sampling Location}

To evaluate the level of microplastic pollution in sediment samples at the receiving water source of some industrial production activities in the Day River basin, the locations of sampling points for this study were selected and described in Table 1 and Figure 1. Each sampling location was selected to appraise the most representative level of microplastic contamination:

Table 1. Sampling locations of sediment from industrial manufacturing waste sources

\begin{tabular}{|l|l|l|l|}
\hline $\begin{array}{l}\text { Sampling } \\
\text { locations }\end{array}$ & Sampling location information & Longitude & Latitude \\
\hline M1 & Receive wastewater from the rubber manufacturing & 21.18 & 105.74 \\
\hline M2 & The receiving wastewater site of the food production & 21.17 & 105.73 \\
\hline M3 & $\begin{array}{l}\text { Near the receiving wastewater site of the electronic } \\
\text { component manufacturing }\end{array}$ & 21.12 & 105.79 \\
\hline
\end{tabular}




\begin{tabular}{|l|l|l|l|}
\hline $\begin{array}{l}\text { Sampling } \\
\text { locations }\end{array}$ & Sampling location information & Longitude & Latitude \\
\hline M4 & The receiving wastewater site of the fertilizer manufacturing & 20.94 & 105.83 \\
\hline M5 & The receiving wastewater site of the battery manufacturing & 20.94 & 105.84 \\
\hline M6 & $\begin{array}{l}\text { 1000m from the receiving wastewater source of the bedding } \\
\text { and pillow manufacturing }\end{array}$ & 20.86 & 105.83 \\
\hline M7 & The receiving wastewater site of the bedding and pillow manufacturing & 20.86 & 105.84 \\
\hline M8 & The receiving wastewater site of the food production & 20.87 & 105.88 \\
\hline M9 & The receiving wastewater river of the mechanical manufacturing & 20.83 & 105.88 \\
\hline
\end{tabular}

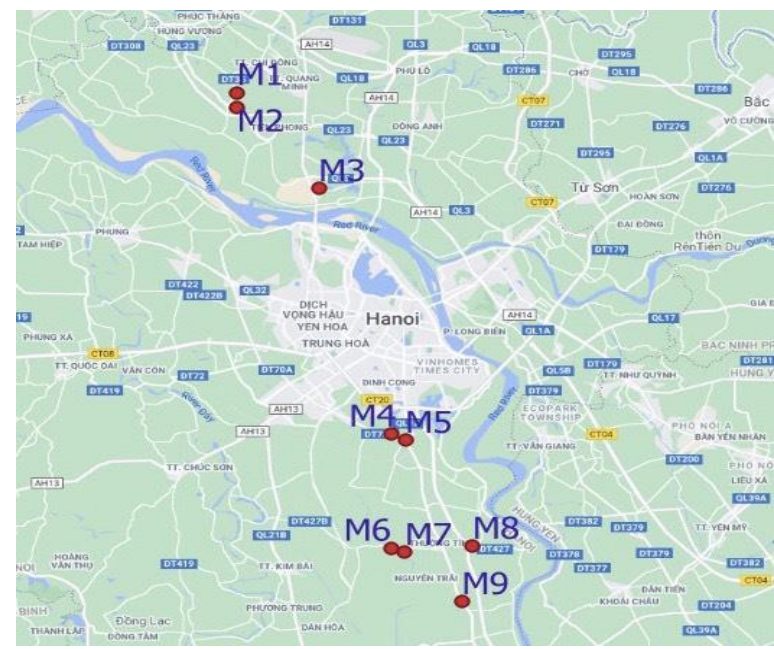

Figure 1. Sampling locations of sediment from industrial manufacturing waste sources.

\subsection{Method of Sampling and Sample Analysis}

At each sampling site, sediment samples were collected using a sediment sampler (3 locations $100 \mathrm{~m}$ apart from each other) and then mixed to obtain approximately $3 \mathrm{~kg}$ of sediment for each spot (three replicates were conducted per spot/three mixed samples per site). Sediment samples were dried at $40{ }^{\circ} \mathrm{C}$ for 72 hours, then sieved with a $1 \mathrm{~mm}$ sieve to remove all debris (shells, leaves, and resins, etc) larger than $1 \mathrm{~mm}$. Ten grams of dried sediment were placed in a $250 \mathrm{~mL}$ beaker with the $30 \%$ $\mathrm{H}_{2} \mathrm{O}_{2}$ solution for 4 hours to remove organic matter in the sample. A saturated salt solution $\left(\mathrm{NaCl}, 1.2 \mathrm{~g} / \mathrm{cm}^{3}\right)$ was used for the microplastic flotation. This step was repeated at least five times to ensure that all microplastics were removed from the sample. The solution after flotation was filtered on a GF/A filter (pore size of $1.6 \mu \mathrm{m}$ ) using a glass vacuum filter. The filters were kept in sterile Petri dishes until examined under a Leica MZ12 microscope for size, morphology and color determination. In this research, based on GESAMP's recommendations, we only focused on microplastics with a minimum length of $300 \mu \mathrm{m}$ and particles with a minimum area of $45000 \mu \mathrm{m}^{2}$ or more. The above analytical conditions were performed according to the procedure clearly described in the recent paper [14].

\section{Results and Discussion}

\subsection{Density of Microplastics in Sediment Samples}

Wastewater has been identified as a source of microplastic pollution in freshwater and terrestrial environments. However, currently, the microplastic pollution investigations in sediment samples collected from the wastewater receiving areas are still limited [13]. 
According to some studies, the pollutants and microplastic concentrations in treated wastewater are reduced by $84-95 \%$ when compared to the original. However, due to differences in wastewater treatment technology and microplastic characteristics, large amounts of microplastics in wastewater and sludge have accumulated in the environment, particularly in sediments [8].

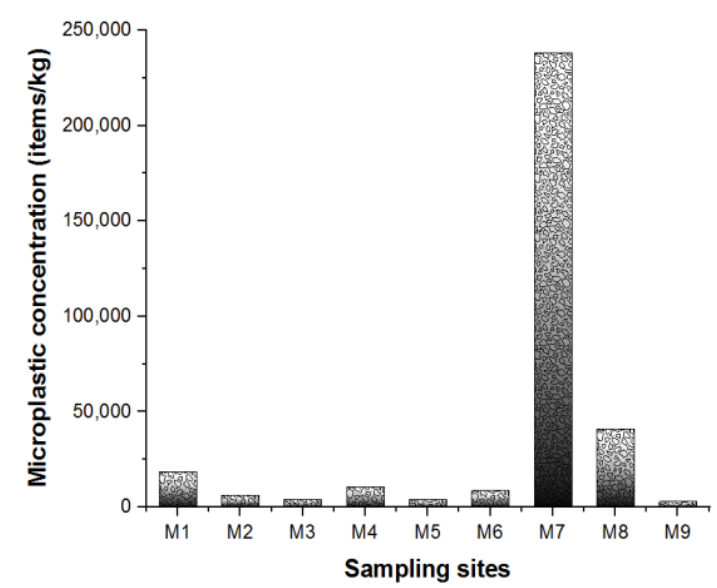

Figure 2. The density of microplastics in the sediment samples collected from some industrial waste sources.

Microplastics were found in all sediment samples in this study (Figure 2). The density of microplastic particles had a wide fluctuation in the range of 2,900-238,200 particles $/ \mathrm{kg}$. At location M7, the highest microplastic density was recorded at 238,200 particles $/ \mathrm{kg}$. The density of microplastics at M8, M1, M4, M6 and M2 locations was 40,900 particles $/ \mathrm{kg}$, 18,500 particles $/ \mathrm{kg}, 10,700$ particles $/ \mathrm{kg}, 8700$ particles $/ \mathrm{kg}$ and 6300 particles $/ \mathrm{kg}$, respectively. At M3, M5 and M9 locations, the detected density of microplastic particles was 4100 particles $/ \mathrm{kg}, \quad 3900$ particles $/ \mathrm{kg}$ and 2900 particles $/ \mathrm{kg}$, respectively. The microplastic density that was observed in the sediment samples in this study $(37133 \pm 76334$ particles $/ \mathrm{kg})$ was significantly higher than in previous studies [5]. The microplastic density found in this research was similar to the results of Wang et al., (2018) on the density of microplastics in a densely populated urban area of the eastern river network of China with an average density of $32947 \pm 15342$ particles/kg [20].

Overall, there was a considerable difference in the density of microplastics found among the study sites $(p<0.05)$. The cause of this difference might be influenced by many complex factors, such as the wastewater source, population density, etc. The microplastic density in the sediment samples at the M7 location was 6-60 times higher compared to the others. This might be due to a large number of bedding and pillow manufacturing facilities in the area, leading to a high number of microplastics entering the wastewater without preventing pollution measurements. In addition, the solid waste (mainly scarp, cotton, yarn, etc.) has been discharged directly on both sides of the road. Rain and wind carry the microplastics from these sources into the soil, water, and other environments.

Sediment samples collected at the other locations were taken near the discharge sites of some industrial zones or high population density areas. Currently, most industrial zones in Hanoi have installed wastewater treatment systems. Some researchers have suggested that the wastewater after treatment might not be the main microplastic source because the concentration of microplastics in the output wastewater of the wastewater treatment system was lower [2]. However, Li et al., (2018) investigated sludge samples from 28 wastewater treatment plants in China and the obtained microplastic density ranged from 1,600 to 56,400 particles $/ \mathrm{kg}$, with an average density of 22,700 particles $/ \mathrm{kg}$ [6]. Another study by Liua et al., (2019) showed that the density of microplastics in the wastewater and sludge was 28,400 and 404,300 particles $/ \mathrm{kg}$, respectively [7]. This showed that wastewater and sludge after passing through the treatment system are still latent sources of microplastic pollution in the environment. Talvitie et al., (2017) also discovered differences in microplastic removal effectiveness due to changes in wastewater treatment technology [16]. Although a large percentage of microplastics in the wastewater treatment 
system have been removed, the wastewater still contains a large amount of microplastics. Besides industrial sources, domestic wastewater and domestic solid waste are also contributing factors to microplastic pollution. Microplastics can pervade ecosystems through many sources, such as wastewater treatment facilities, runoff from urban areas, entertainment activities, agriculture, and industry [1]. In Hanoi, about 95\% of the capital's wastewater is disposed into the rivers without treatment (about $450000 \mathrm{~m}^{3}$ per day) [4]. Therefore, domestic wastewater could also be a major cause of microplastic accruement in the soil and water environments. Directly discharging untreated wastewater from various sources (domestic waste, untreated sewers, laundry, commercial solid waste, etc.) could also lead to an enormous concentration of microplastics in sediment samples.

In Vietnam, the obtained results from this study are the first step towards assessing the status of microplastic pollution in sediments of the receiving wastewater source from some industrial production facilities. Further studies are needed to determine the microplastic pollution in sludge, input wastewater and post-treatment wastewater before it is emitted into the surrounding environment.

\subsection{Shape, Size and Color Characteristics of Microplastic in Sediment Samples}

\subsubsection{Shape of Microplastics}

Shape is an important factor in microplastic classification. In this study, microplastic shapes in sediment samples at 9 study sites were observed using a Leica MZ12 microscope on a Whatman GF/A filter. The abundance of microplastic shapes is shown in Figure 3. Fragments and fibers were the most abundant microplastics found in sediment samples at these sites.

The fibers were the dominant microplastic shape in sediment samples with a range from 59 to $94 \%$ while the fragments were less prevalent accounting for 6 to $41 \%$ of the total. At M6 and M7 locations, the fiber microplastics were quite high, above $90 \%$. These were the sites that received wastewater from the bedding and pillow production craft villages. Cesa et al., (2017) presented that the increasing consumption of laundry and textiles led to more frequent detection of fiber microplastics. In textile manufacturing, fiber microplastics are also produced during the cutting and joining processes, which then go into the wastewater and accumulate in the sediment [3].

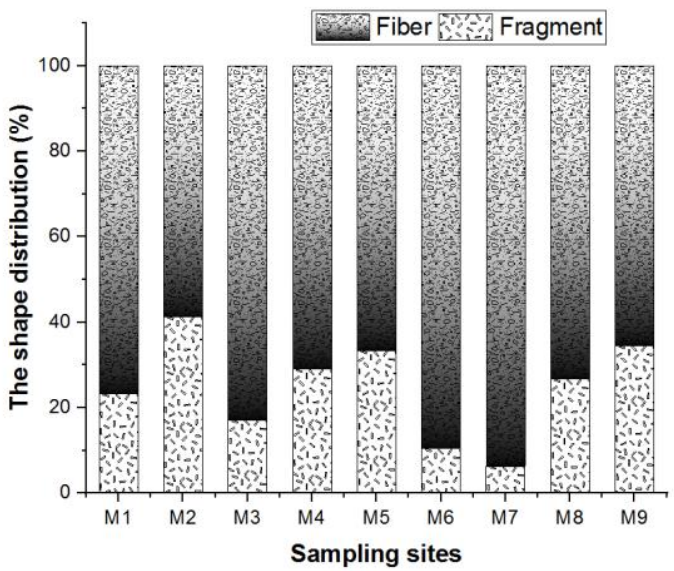

Figure 3. The shape distribution of microplastics in sediment samples.

The density of microplastics at M3, M1, M2, M4, M5, M8 and M9 locations were in the range of $23-41 \%$, which were higher than at M7 and M6 (6\% and 10\%, respectively). Mahon et al., (2017) also claimed that the microplastic fibers could be mainly derived from the washing and discharging processes of the fiber industry, while the fragment microplastics might be related to plastic production or derived from plastic packaging, cosmetics, and personal care products such as toothpaste, face masks and soaps [9]. Mason et al., (2016) stated that in wastewater from the wastewater treatment systems, fiber microplastics also accounted for the highest proportion, followed by fragment microplastics, finally foam and pellet microplastics accounted for a very small fraction [10]. In general, fibers and fragments are the two main forms of microplastics in the waste sources (from the wastewater treatment plants, the domestic activities, the air,...). This also explained the high occurrence of these microplastics in the sediments. 


\subsubsection{Size of Microplastics}

Similar to the shape of microplastics, their size is also a significant factor affecting the appearance of microplastics in the environment. Because microplastics are very small, they could easily penetrate the food chain of the ecosystem. Therefore, it is necessary to determine the size of microplastic particles in the sediment samples. In Figure 4, the distribution of microplastic particle sizes in the sediment samples at wastewater discharged locations of some industrial production activities was presented. The collected microplastics in this study were in the $<1000-9000 \mu \mathrm{m}$ size range for fiber particles and in the $<200,000-2,100,000 \mu \mathrm{m}$ size range for fragment particles. Microplastic particles in the form of fragments and fibers at the study sites were various in size. The size distribution of microplastic fibers detected at all sites in this study was mainly divided into $<1000 \mu \mathrm{m}$, 1000-2000 $\mu \mathrm{m}, 2000-3000 \mu \mathrm{m}, 3000-4000 \mu \mathrm{m}$ and $4000-9000 \mu \mathrm{m}$ as shown in Figure $4 \mathrm{a}$. Microplastics with sizes $<1000 \mu \mathrm{m}$ and 1000-2000 $\mu \mathrm{m}$ accounted for the largest proportions, with $21.05-37.84 \%$ and $39.74-61.17 \%$. Microplastics with sizes of 2000-3000 $\mu \mathrm{m}$, $3000-4000 \mu \mathrm{m}$ and 4000-9000 $\mu \mathrm{m}$ accounted for a lower proportion in the range of $7.89-23.08 \%, 0-11.54 \%$ and $0-10.81 \%$. Regarding the size distribution of the microplastic fragments detected in this study, it was mainly divided into the areas of $<200000 \mu \mathrm{m}^{2}$, 200000-400000 $\mu^{2}, 400000-900000 \mu \mathrm{m}^{2}$ and 900000-2100000 $\mu \mathrm{m}^{2}$ (Figure 4b). In which, the occurrence frequency of microplastic fragments in the studied sites accounted for $46.15-88.89 \%$, $0.00-29.03 \%, 0.00-19.35 \%$ and $0.00-15.38 \%$.
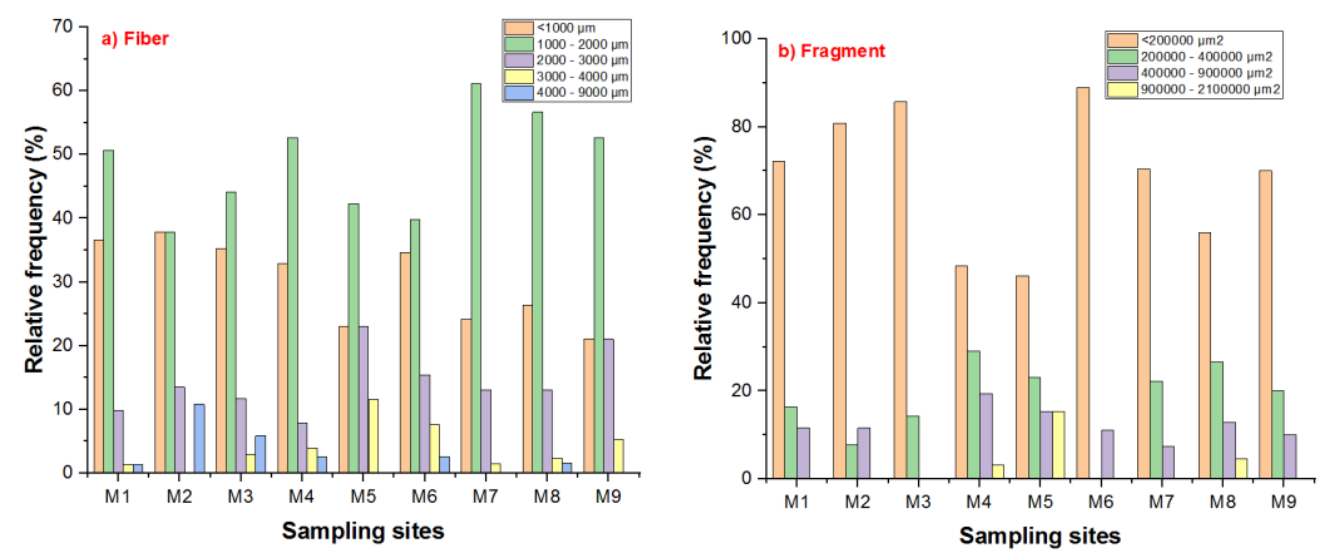

Figure 4. The size frequency of microplastics in sediment samples.

In this research, microplastics with sizes $<1000 \mu \mathrm{m}$ and 1000-2000 $\mu \mathrm{m}$ had the highest count of $65.38-87.32 \%$ for the fiber shape. Similar to the fragments, microplastics with areas in the range $<200000 \mu \mathrm{m}^{2}$ account for a high ratio, accounting for $46.15-88.89 \%$. Wu et al., (2019) also reported that the size distribution trend of microplastics resembled the results in the water and sediment samples in Bohai Bay, China [21]. Publications on the size of microplastics in wastewater also showed that microplastics in the size of $<2000 \mu \mathrm{m}$ were dominated, while 2000-5000 $\mu \mathrm{m}$ microplastics accounted for a very low percentage [22]. The disappearance of larger debris could be attributed to mechanical erosion by settlement and faulting, chemical or even biological degradation and other hidden reasons related to the fact that the larger and heavier plastic particles are, the easier they are adsorbed and deposited during transport.

3.2.3. Color Distribution of Microplastics

During the manufacturing process, plastics are often dyed to create their properties such as ductility, durability, electrical conductivity, etc. In addition, the color of microplastics is 
beneficial in plastic source identification as well as potential contamination [19]. The research data in Figure 5 showed that microplastic colors from sediment samples could be distinguished by white, black, red, blue, yellow, greenand purple.

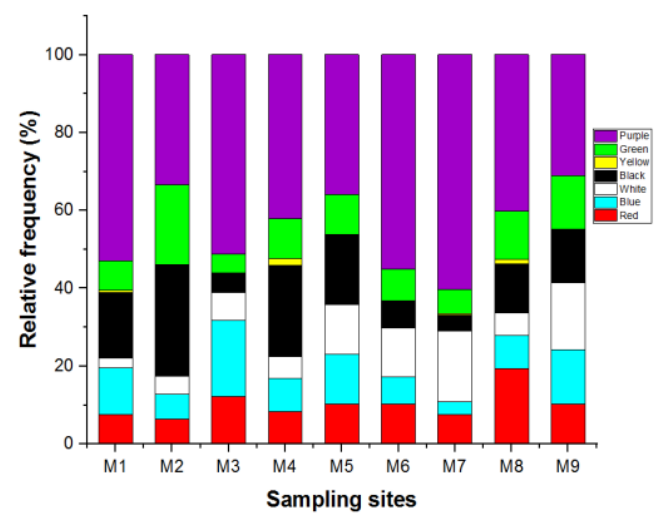

Figure 5. Color variation of microplastics in sediment samples.Regarding the color richness of microplastics $(n=72)$, the majority of microplastics were purple $(44.69 \pm 10.64 \%)$ and black $(14.31 \pm 8.34 \%)$. Green, blue, white and red microplastics accounted for $10.44 \pm 4.79 \% ; 10.18 \pm 4.85 \% ; 9.68 \pm 5.67 \%$ and $10.25 \pm 3.86 \%$, respectively. Yellow microplastics were rarely observed and accounted for $0.45 \pm 0.67 \%$. The research results revealed that the color of microplastic particles in the collected sediment samples was quite diverse. Colored microplastic particles were high in ratio. The color diversity of microplastics was also detected in the after-treatment wastewater and sludge, surface water, and river sediments of the previous studies $[11,19,22]$. This might indicate that the occurrence of large amounts of colored microplastics in the above study sites was heavily influenced by industrial and urban waste sources.

\section{Conclusion}

Sediment samples, were collected at 9 locations that received wastewater from several industrial production activities in the Day River basin and contained microplastics with a high density, ranging from 2,900 to
238,200 particles $/ \mathrm{kg}$. Fibers and fragments were the most abundant microplastics found in sediment samples at these sites, accounting for $59-94 \%$ and $6-41 \%$, respectively. The size of the microplastics obtained ranged from $<1000-9000 \mu \mathrm{m}$ for fibers and $<200,000-2,100,000 \mu \mathrm{m}^{2}$ for fragments. Microplastics with sizes $<1000 \mu \mathrm{m}$ and 1000-2000 $\mu \mathrm{m}$ accounted for the largest proportions with $21.05-37.84 \%$ and $39.74-61.17 \%$. The color of microplastic particles in the collected sediment samples was quite diverse. Colored microplastic particles had a sizable percentage of the total. These data are the first step toward assessing microplastic pollution at waste sources.

\section{Acknowledgements}

This research is funded by the Vietnam National Foundation for Science and Technology Development (NAFOSTED) under the $11 / 2020 / T N$ grant number and the Senior Researcher Support Program NCVCC 30.04/20-20. The authors sincerely thank the Science Development Fund and the Vietnam Academy of Science and Technology for funding the implementation.

\section{References}

[1] J. C. Anderson, B. J Park., V. P. Palace, Microplastics in Aquatic Environments: Implications for Canadian Ecosystems, Environ, Pollut, Vol. 218, 2016, pp. 269-280.

[2] S. A Carr, J. Liu, A. G. Tesoro, Transport and Fate of Microplastic Particles in Wastewater Treatment Plants, Water Res, Vol. 9, 2016, pp. 174-182.

[3] F. S. Cesa, A. Turra, J. B. Ramos, Synthetic Fibers as Microplastics in the Marine Environment: A Review from Textile Perspective with a Focus on Domestic Washings, Sci, Total Environ, Vol. 598, 2017, pp. 1116-1129.

[4] P. M. Hoai, N. T. Ngoc, N. H. Minh, P. H. Viet, M. Berg, A. C. Alder, W. Giger, Recent Levels of Organochlorine Pesticides and Polychlorinated Biphenyls in Sediments of the Sewer System in Hanoi, Vietnam, Environ, Pollut, Vol. 158, No. 3, 2010, pp. 913-920.

[5] A. A. Horton, C. Svendsen, R. J. Williams, D. J. Spurgeon, E. Lahive, Presence and Abundance of 
Microplastics in Sediments of Tributaries of the River Thames, UK, 2017, pp. 6-7.

[6] X. Li, L. Chen, Q. Mei, B. Dong, X. Dai, G. Ding, E. Y. Zeng, Microplastics in Sewage Sludge from the Wastewater Treatment Plants in China, Water Res, Vol. 142, 2018, pp. 75-85.

[7] X. Liua, W. Yuana, M. Dia, Z. Lia, J. Wanga, Transfer and Fate of Microplastics During the Conventional Activated Sludge Process in one Wastewater Treatment Plant of China, Chemical, J. Engineering, Vol. 362, 2019, pp. 176-182.

[8] A. L. Lusher, R. R. Hurley, C. Vogelsang, Microplastics in Sewage Sludge: Captured but Released? In Book: Microplastics in Water and Wastewater, K. K. Hrissi, K. K. Ioannis, IWA Publishing, 2019.

[9] A. M. Mahon, B. O’Connell, M. G. Healy, I. O’Connor, R. Officer, R. Nash, L. Morrison, Microplastics in Sewage Sludge: Effects of Treatment, Environ, Sci, Technol, Vol. 51, 2017, pp. 810-818.

[10] S. A. Mason, D. Garneau, R. Sutton, Y. Chu, K. Ehmann, J. Barnes, P. Fink, D. Papazissimos, D. L. Rogers, Microplastic Pollution is Widely Detected in US Municipal Wastewater Treatment Plant Effluent, Environ, Pollut, Vol. 218, 2016, pp. 1045-1054.

[11] F. Murphy, C. Ewins, F. Carbonnier, B. Quinn, Wastewater Treatment Works (WwTW) as a Source of Microplastics in the Aquatic Environment, Environ, Sci, Technol, Vol. 50, No. 11, 2016, pp. 5800-5808.

[12] P. L. Ngo, B. K. Pramanik, K. Shah, R. Roychand, Pathway, Classification and Removal Efficiency of Microplastics in Wastewater Treatment Plants, Environ, Pollut, 2019.

[13] C. Rolsky, V. Kelkar, E. Driver, R. U. Halden, Municipal Sewage Sludge as a Source of Microplastics in the Environment, Current Opinion in Environ, Sci, Health, Vol. 14, 2020, pp. 16-22.

[14] E. Strady, T. H. Dang, T. D. Dao, H. N. Dinh, T. T. D. Do, T. N. Duong, T. T. Duong, D. A. Hoang, T. C. K. Le, T. P. Q. Le, H. Mai, D. M. Trinh, Q. H. Nguyen, Q. A. T. Nguyen, Q. V. Tran, T. N. S. Truong, V. H. Chu, V. C. Vo, Baseline Assessment of Microplastic Concentrations in Marine and Freshwater Environments of a Developing Southeast Asian Country, Vietnam, Mar, Pollut, Bull, 2021.

[15] J. Sun, X. Dai, Q. Wang, M. C. M. V. Loosdrecht, B. J. Ni, Microplastics in Wastewater Treatment Plants: Detection, Occurrence and Removal, Water, Res, Vol. 152, 2019, pp. 21-37.

[16] J. Talvitie, A. Mikola, O. Setälä, A. Koistinen, Solutions to Microplastic Pollution - Removal of Microplastics from Wastewater Effluent with Advanced Wastewater Treatment Technologies, Water Res, Vol. 123, 2017, pp. 401-407.

[17] P. Vermeiren, C. C. Muñoz, K. Ikejima, Sources and Sinks of Plastic Debris in Estuaries: a Conceptual Model Integrating Biological, Physical and Chemical Distribution Mechanisms, Mar, Pollut, Bull, Vol. 113, 2016, pp. 7-16.

[18] M. Wagner, C. Scherer, D. A. Muñoz, N. Brennholt, X. Bourrain, S. Buchinger, E. Fries, C. Grosbois, J. Klasmeier, T. Marti, S. R. Mozaz, R. Urbatzka, A. D. Vethaak, M. W. Nielsen, G. Reifferscheid, Microplastics in Freshwater Ecosystems: What We Know and What We Need to Know, Environ, Sci, Europe, Vol. 26, No. 1, 2014, pp. 1-9.

[19] W. Wang, A. W. Ndungu, Z. Li, J. Wang, Microplastics Pollution in Inland Freshwaters of China: A Case Study in Urban Surface Waters of Wuhan, China, Sci. of The Total Environ, Vol. 575, 2017, pp. 1369-1374.

[20] Z. Wang, B. Su, X. Xu, D. Di, H. Huang, K. Mei, R. A. Dahlgren, M. Zhang, X. Shang, Preferential Accumulation of Small $(300 \mu \mathrm{m})$ Microplastics in the Sediments of a Coastal Plain River Network in Eastern China, Water Res, Vol. 144, 2018, pp. 393-401.

[21] N. Wu, Y. Zhang, Z. Zhao, J. He, W. Li, Y. Ma, Occurrence and Distribution of Microplastics in Surface Water and Sediments of Two Typical Estuaries in Bohai Bay, China, Environ, Sci, Proc, Imp, Vol. 21, 2019, pp. 1143-1152.

[22] Y. Zhang, S. Kang, S. Allen, D. Allen, T. Gao, M. Sillanpaa, Atmospheric Microplastics: A Review on Current Status and Perspectives, Earth Sci, Rev, Vol. 203, 2013, pp. 103-118. 